
AC 2012-3292: DEVELOPING MODEL FOR CROSS-CULTURAL SER-
VICE LEARNING IN DEVELOPING COUNTRIES

Dr. Kurt M. DeGoede, Elizabethtown College

Kurt DeGoede Associate Professor of engineering and physics, Elizabethtown College. DeGoede is currently working on developing a collaborative study abroad program in West Africa built around a design course based in service engineering. Many of these projects include work with renewable energy systems. His research interests are in the areas of biomechanics and the modeling of dynamic systems. Current projects include collaborative work with faculty and students in occupational therapy and an orthopedic hand surgeon, developing clinical instruments for conducting therapy and assessing human movement in patients undergoing rehabilitation.

Dr. Jennifer Kadlowec, Rowan University

Dr. Momodou Jain 


\section{Developing Model for Cross-Cultural Service Learning in Developing Countries}

\section{Overview}

This paper outlines a developing model for engaging in community based service learning projects in a developing country (The Gambia, West Africa). The model here strives to foster multicultural teams of students collaborating in multicultural peer to peer teams. When the solutions to problems of "local and global public good" are developed in situ, the local population is empowered to solve other related problems and sustain any system developed over the expected life of that system. This program recognizes the existing pattern of dependency, and is designed to overcome that pattern by working side by side with Gambian university students and faculty, along with community leaders.

This developing program specifically aims to develop students' abilities to design appropriate solutions, function in multi-disciplinary teams and understanding engineering solutions in a global context. Gambian students can easily take designs developed for one community as a pilot model and extend these to other villages. All students gain transferrable skills in developing sustainable and appropriate technologies, in the context of a total design approach including long-term factors such as energy consumption, local materials, durability, maintenance and economic sustainability of the project.

While the first academic year of this collaboration produced several tangible results and great first steps, if this year's results were the conclusion, we would be disappointed. However we find encouragement from the founder of the EPICS program at Purdue University "When you start [an engineering Service-Learning program], start small and imperfect... Start with something and build." 1 The past 15 months represent very successful "imperfect" first steps in a long collaborative intervention.

\section{Model for Collaboration}

A few simple ideas from the book When Helping Hurts: How to alleviate poverty without hurting the poor... and yourself, formed the basis for the model developed for a new program of service learning projects based in The Gambia. ${ }^{2}$ These projects are in the "development" stage, as opposed to "relief" and "rehabilitation." The book highlighted the success of interventions based on "People and Processes, Not Projects and Products." Further, any "development" intervention should be asset based, not need based. In engineering design terms: start with the resources and limitations (of the community you are working with) along with the "problem" and design ways to address that problem within the limitations of that community. "Give me your tired, your poor, and their ASSETS." Such a philosophy will move projects toward economically sustainable solutions for the community. Solutions will need to be designed within the resources of the community being served. As such, other villages will be able to replicate the success of the one village. The book also highlights the ideas described by Bérengère de Negri et al., Table $1 .{ }^{3}$ 
Table 1: Collaborative Mode of Participation ${ }^{3}$

\begin{tabular}{|c|c|c|}
\hline $\begin{array}{l}\text { Mode of } \\
\text { Participation }\end{array}$ & Involvement of Local People & $\begin{array}{l}\text { Relationship of Research } \\
\text { \& Action to Local People }\end{array}$ \\
\hline Co-option & $\begin{array}{l}\text { Token representatives are chosen, but have no real input or } \\
\text { power. }\end{array}$ & $\mathrm{ON}$ \\
\hline Compliance & $\begin{array}{l}\text { Tasks are assigned with incentives; outsiders decide } \\
\text { agenda and direct the process. }\end{array}$ & FOR \\
\hline Consultation & $\begin{array}{l}\text { Local opinions are asked; outsiders analyze and decide on } \\
\text { a course of action. }\end{array}$ & FOR/WITH \\
\hline Cooperation & $\begin{array}{l}\text { Local people work together with outsiders to determine } \\
\text { priorities; responsibility remains with outsiders for } \\
\text { directing the process. }\end{array}$ & WITH \\
\hline Co-learning & $\begin{array}{l}\text { Local people and outsiders share their knowledge to create } \\
\text { new understanding and work together plans, to form action } \\
\text { with outsider facilitation. }\end{array}$ & WITH/ BY \\
\hline Collective & $\begin{array}{l}\text { Local people set their own agenda and mobilize to, carry it } \\
\text { out in the absence of outside initiators and facilitators. }\end{array}$ & BY \\
\hline
\end{tabular}

The co-learning model of de Negri is based on integrated multicultural design teams working on these problems. Even after several months in a community, it can be a challenge to truly understand the local culture and environment. Others have compared Engineering service work to the long process of public health as opposed to the quick fix of surgery, arguing that the typical service project does more social justice harm than good, despite the noble intentions. ${ }^{4}$ Many projects only increase dependency and reinforce social power stereotypes.

Robert Calderisi gives two examples of successful intervention through participation modes clearly in the lower rows of this chart as he looks to the future for development in Africa ${ }^{5}$ :

What made the difference? Short of alternatives and unwilling to wait for the government, the nurse had convinced the women of the village to contribute to the running of the clinic. She had no water, so she had contacted an Italian charity to repair the well. "So the government's money came in handy," I told the schoolteacher. There was a twinkle in my friend's eye. "They never gave us a penny," he said. "After the elections, they forgot about us entirely." "Then how did you finance all of this?" I asked. "With your \$2,000 and the money we raised selling banana cuttings to new members," he replied. "I'm astonished," I said. He smiled. "You shouldn't be. You always told us that money was not the major obstacle to progress in Africa."

William Easterly describes this dichotomy simply as a contrast between Planners verses Searchers. Planners have good intentions, but little follow through or accountability, they determine what to supply, but don't know the reality on the ground and think they have all the answers. Searchers find things that work and apply them, accept responsibility, find out what is in demand, adapt to local conditions, admit they don't have the answers and find out about 
reality on the ground. In summary "The right plan is to have no plan." External searchers can do specific good things for the poor. Local searchers solve their own problems. ${ }^{6}$

Others reinforce the call for the use of local resources and collaborations centered on collaboration as equals; "fighting poverty is not a matter of giving money, but a matter of giving hope" and the Gambian Youth's "future is in their own hands." 7 Habitat for Humanity's sweat equity model is a way to develop the sense of ownership. ${ }^{8}$ Engineers without Borders has also adopted an model requiring community involvement in their projects. ${ }^{9}$

Finally, an admirable model for a long term relationship through a service learning initiative is the Village Empowerment (VE) program at University of Massachusetts Lowell with 13 years of continuous work with now 35 villages in a region of Peru involving hundreds of students (100 who have traveled to Peru on at least one of the semi-annual trips). ${ }^{8}$ Part of the SLICE program (Service Learning Integrated throughout the College of Engineering) at UML, which provides a service learning experience in every semester for every engineering undergraduate. ${ }^{1}$ Transition to the villagers designing and maintaining their own systems is a challenge although the VE program is making progress. ${ }^{8}$

Typical engineering service projects (particularly in the developing world) are in the realm of cooption (token local input) and consultation (local opinions are asked but analysis and decisions are made by outsiders). Many are also short term and focus on a quick fix to a specific problem. By focusing on partnering Gambian students and faculty with those from the US, the projects here should operate in the realm of co-learning (local people and outsiders share knowledge and work together to solve problems) moving toward collective action (communities setting their own agenda and solving problems without outside initiators or facilitators). This collaboration is being developed as a long term collaborative undertaking to be continued indefinitely.

Solving the Right Problem

If you don't have the problem fully understood (which includes the reality of day to day life on the ground and the culture of the society and village) you are likely solving the wrong problem. As an anecdotal example, a well meaning group installed numerous beautifully fabricated composting toilets in a South American village. Only to come back a year later to discover them all turned into very expensive chicken coops. Another recent story, in Mechanical Engineering magazine, told of similar problems regarding water filtration systems; where villages did not want or need the type of system being designed. ${ }^{10}$ Solving the wrong problem doesn't do anybody any good. A number of NGO aid projects have failed for this reason and the parallel problem: a lack of community involvement. ${ }^{11}$ Paul Farmer (Partners in Health) shared his criticism of many engineering service projects in Haiti along these lines: in his experience three years after projects were completed, many systems have failed, and the original designers have no commitment to the project. ${ }^{12}$

Just with the example of photovoltaic power systems, there are hundreds of non-operational PV systems in The Gambia that were put in place by caring NGOs or individuals. A good engineering solution cannot be developed without understanding the culture and environment in which the system will operate. Technology transfer without good market analysis or customer 
needs and resource analysis seldom produces lasting impact.

Sometimes the difficulty stems from a failure to understand the real problem that needs to be addressed. Too often the problem is defined without real communication with the local population or customer. Or, systems are designed from a western framework and utilize technologies that are not appropriate for the local environment. ${ }^{10}$

Working side by side with the faculty and students in The Gambia will help us to avoid these traps. The systems are more likely to realistically fit within the limitations of the local environment since members of the design team will be from the local society. Good engineering solutions will emerge from long term collaborative work, with continuous and substantial back and forth communication with populations being served by the project work.

\section{Economic Sustainability}

Many programs lament the high fundraising requirement of these programs. ${ }^{13,14}$ We need to break out of this model! External funding of the projects only continues the cycle of dependency that is so completely entrenched in Gambian society. Designing systems or devices that the local community can afford, within an economically sustainable constraint, is just good total design. If we need to raise funds for the projects it is unlikely economically sustainable for the communities. External funding for scholarships for student travel, equipment for the UTG labs and funding for developmental prototypes would be acceptable.

While the problems faced in the developing world seem simple (or "mundane"), the solutions within sustainable constraints are not and require long term "sophisticated research." Solutions to these problems require extensive collaborative efforts between engineers, ecologists, sociologists, economists, government agencies, NGO's and community groups. ${ }^{15}$ Sustainable design focuses on solutions to environmental problems within the context of the intersections of social, economic and ecological systems. And the language of 'design' facilitates the bridging of the technical work and social analysis. ${ }^{16}$

The end goal of an economically sustainable design that will be self propagating will be more likely when following a design process focused on local resources and materials, as captured nicely in a flowchart adapted from McGarvey (Figure 1). ${ }^{17}$ Low cost is a key design criteria the system should be practical for deployment in other villages without substantial fund raising demands. The solutions developed must also work within the local environmental conditions (high levels of heat, humidity and dust), and fit within traditional lifestyles and practices. The integration of the local students and faculty as leaders on these projects should help to avoid ending with a non sustainable solution that will not migrate through the country. ${ }^{18}$ 


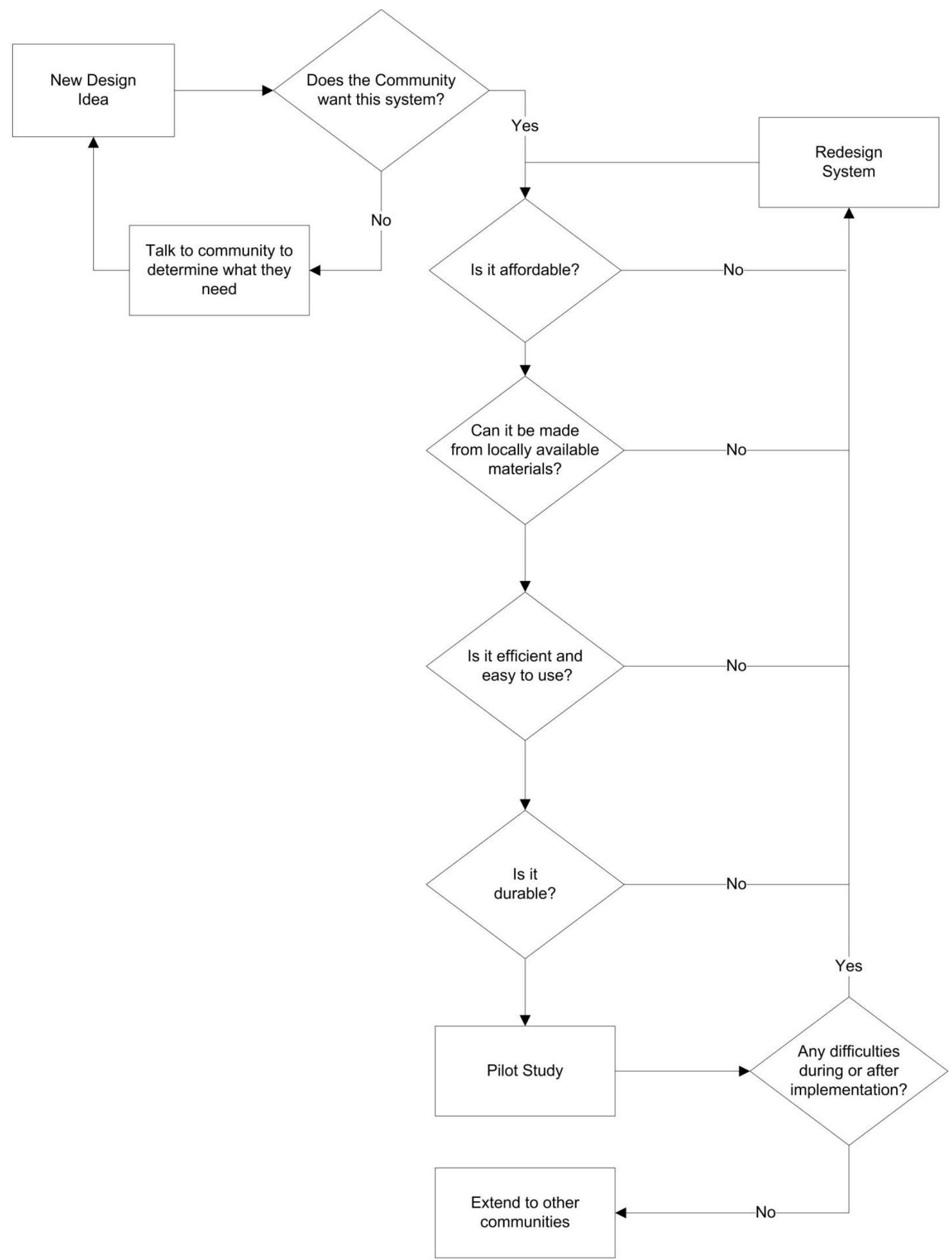

Figure 1: Engineering Aid Design Flow ${ }^{17}$ 
At the state level in many African countries, the adverse effect of excessive levels of aid leading to corruption and dependency on aid and a lack of accountability to the local population has been documented. ${ }^{19}$ Moss, et. al. indicated that "we join other analysts who have advocated substantial increases in funding for regional and global public goods, such as agricultural research or anti-malaria research." We saw evidence of this type of dependency during our site visits last January where villages were looking for handouts from tourists as their sustainability plan for staff salary and medication supplies. The effect of corruption on top down aid can be crippling. 5,20

When the solutions to these problems of "local and global public good" are developed locally the local population is empowered to solve other problems and sustain any system developed over the expected life of the system. These projects are designed with the context of the five factors

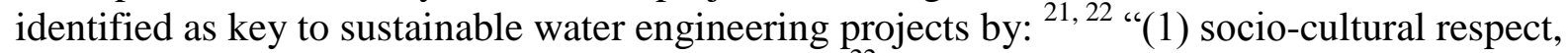
(2) community participation [community demand, ${ }^{22}$ ] (3) political cohesion, (4) economic sustainability [local financing and cost recovery], and (5) environmental sustainability" and "dynamic operation and maintenance." In this way we can work toward the ideal voiced by William Kamkwamba in his popular autobiographical account The Boy Who Harnessed the Wind, "creating a new kind of Africa, a place of leaders instead of victims, a home of innovation rather than charity." 23

\section{Collaborative Design Structure}

The program will allow undergraduate Engineering students to study and put into practice appropriate technology research and design skills in the context of a developing country, The Gambia, in collaboration with local students and communities. This program is being developed around multi-cultural/multi-disciplinary design teams working on community based service projects while studying engineering design methodology through a 3-credit Total Design ${ }^{24}$ course introduced into the University of The Gambia, UTG, curriculum. In student teams made up of both Gambian and US students, the goal is to develop sustainable business structures likely led by graduating UTG students to propagate solutions to other communities (Figure 2).

US students will be able to participate in Gambian projects as [1] study abroad students enrolled for a term at UTG, [2] as part of a design team at their home institution collaborating with colleagues at UTG, and/or [3] traveling in January between semesters or over the summer for short term study abroad courses and site visits for relationship building, data gathering, implementation, testing, maintenance and/or training. Students would be encouraged to include a semester at UTG as part of a multiyear participation in one or more projects serving a community in The Gambia. Gambian students can participate through the design course, the developing Practical Training Program for students and recent alumni, and potentially through a sponsored semester at a collaborating institution in the US. 


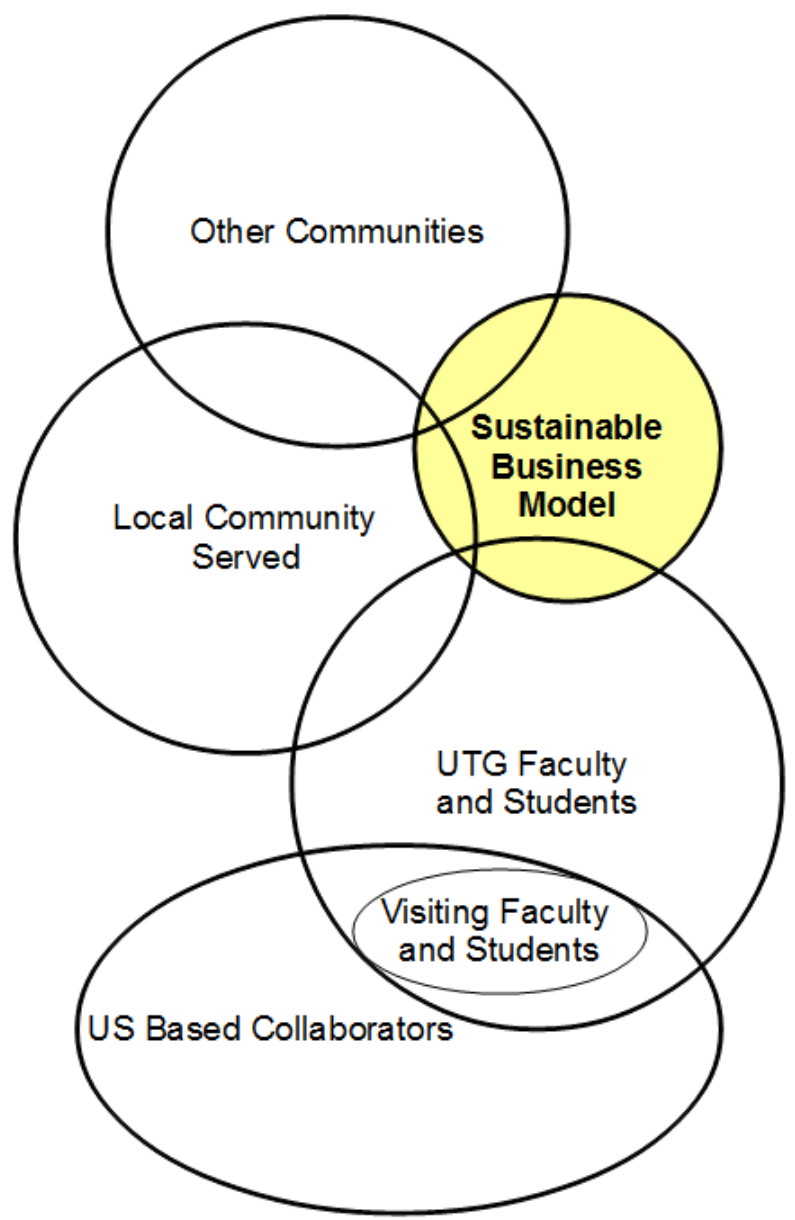

Figure 2: Collaborative Service Learning structure.

Collaboration between students in non-technical fields will particularly enrich this program. The projects we envision for this program will require expertise in market analysis, social services and entrepreneurship. We hope to create a model where US based students in other disciplines could participate through senior project work in their own departments collaborating with the engineering students.

At Stanford, an approach has been adopted utilizing collaboration with NGO's as an internship for service learning experiences. ${ }^{13}$ An internship model could be a great way to package the short term visit option ([3], above) - the Stanford program is a six week (minimum) internship at the site working for the partner NGO. One challenge for Stanford, and undoubtedly others, is the burden of proof for meeting design requirements of the program to the satisfaction of accreditation requirements with service learning projects.

Educational Goals can mislead aid. What is the priority? Putting the customer need first can be the educational objective - reflecting real world customer driven design. Conflict between educational goals of the learning experience and goals of serving a community was identified as a major factor in the failure of previous service learning projects. ${ }^{4}$ This team also identified the tendency for engineers to put product over process "technical functionality over participatory practice," can lead to nice technical innovation, but poor sustainability within the developing 
community.

The tendency is also parallel to moving too quickly into product development without understanding the full problem at hand - without understanding the local cultural, environmental, social and economic constraints external engineers are often solving the wrong problem. And while our solutions may be terrific solutions to the problem defined, they end up rusting in the corner of a West African compound because it was the right answer to the wrong question.

Through a structure based on peer to peer collaboration between students and faculty from the US and UTG this model operates in the "co-learning" mode of participation. The educational outcome of the service learning project is that UTG students come away from the project knowing they can solve these kinds of problems without external direction or expertise. This shatters the culture of dependency that is so deeply entrenched in many developing countries. By developing local capacity through UTG the program strives to enable "collective" action by individuals and communities on future projects.

Initial Results

In the spring of 2011, faculty and students at UTG collaborated with one US faculty member and one US based physics student visiting UTG during that semester to redesign failed photovoltaic systems at two installations. These systems needed to be reexamined within the context of the setting in which they have been installed. The systems should be developed with as many local materials and technologies as possible. Scientifically, the challenge for the design team was to find the intersection of the existing technology for sustainable energy systems and the appropriate technologies for the rural Gambian villages they are working with.

The frustration of working with locally available materials can be staggering. There are only a handful of options for PV modules and controllers in the shops in the commercial center of The Gambia. Batteries are even worse; the only readily available batteries are just big car/truck batteries - not optimal for PV systems. Other options if you can find them are priced out of most applications. The car batteries could be OK, if they are not drained very far, but many abuse them and the batteries need to be replaced frequently. Conveying an understanding of how to use and maintain a system is a challenge that must be addressed.

The US based student was teamed with three Gambian students working with an NGO in Pirang. The PV system at the main community center and guest house was not working properly and they were looking to expand their water pumping capacity for irrigation of the center's community farm plots. They currently had a PV powered water pump and a 4000 liter tank. The team did a thorough analysis of the system for the center and developed recommendations on how to repair and optimize the equipment they have. Their report detailed the best way to utilize all of the center's available modules and reconfigure the loads to add additional loads without expanding the current hardware. They also projected the increased output of their existing pump with the addition of a second 4000 liter tank (already ordered at the time of the project).

In Pirang the ownership of the PV resources clearly resides in the hands of the Gambian director, 
and he takes the maintenance of the system seriously. In Pirang, the student's recommendations will be immediately valuable at the center as they will be taking delivery of a second water tank very soon and look to increase the capacity of the main PV system soon.

The director of the center in Pirang immediately began to put action items into practice and clearly valued the data in the students' analysis. The students came away from their meeting with the director of the center beaming. In late July 2011, we received a report from director, that he had implemented all of the student team's recommendations. They are running for 12 hours a day on their main PV system without issue and expect to be able to irrigate the entire farm plot in the dry season.

"I think the Pirang group had more fun today." Hassum summed up the delivery of their final report in Gunjur. While the students did essentially the same work in quantity, content and quality, the lack of ownership in Gunjur led to a frustrating session. The man the students were working with was the chief doctor at the clinic. He doesn't have the time to manage the power systems and understandably seemed to want the students to come in and solve all his problems. Unfortunately, this was beyond the scope of the student's work for the semester, and would likely only further propagate the ownership issue. This problem also manifested itself in a total lack of understanding of their system, and therefore improper management of the system and very poor maintenance practices. However, a few paths forward emerged at the close of the project last spring. First, on our drive back from Gunjur, as typical when you have room and someone is going the same way, we picked up a gentleman we had met briefly at the clinic who was heading our way. We discovered he is the accountant for the health center, he was very interested in the students' work, and quickly requested a copy of their report. He promised to act on it soon, as he saw that the recommendations would save the clinic money.

Our work with the Gunjur health center has brought us face to face with all of the challenges described in this paper. We wish we could have solved all their problems, but we can't. In fact we needed to remind ourselves that previously someone did 'solve all their problems' for them, and here we were with the same symptoms 'solved' just a few years ago. We hope we have started down a road that will lead us to a better more sustainable solution. Our work here will continue and we are looking forward to our continued collaborations.

In fall 2011, we have extended our initial collaboration to include a partnership between the Engineers Without Borders chapter at Rowan University and students and faculty at UTG. As this manuscript is being drafted, students and faculty from Rowan are preparing to travel to The Gambia (in January 2012) to visit eight villages along the Kudang-Kuntaur road in the eastern region of the country with faculty and students from UTG. Rowan EWB teams are working on several projects including the development of an appropriate technology water pump in collaboration with Concern Universal and a system to make cooking fuel from waste peanut shells. The Gambia is filled with a particular hand pump (Mark II), but finding the necessary imported parts for it can be quite difficult and expensive. The group travelling in January will be working with villages in particular on developing water pumping sustainability. The team was just informed a couple of months before departure that new solar water pumping systems were recently installed in several of the villages. This development changes the nature of the team's work with the villages, they are now focused on a long term sustainable solution including 
effective maintenance.

Future Projects

A team of UTG students is continuing to work toward a sustainable solution at the Gunjur site. A team of US based students, mostly engineering students but also including two political science students who spent one semester (Fall 2011) at UTG, are working to build on the experience at Pirang to develop small scale power systems for villages or cooperative sets of compounds. Many community groups do not have the upfront resources for such a system. To attempt to address this difficulty, we have set up a fund within the Norwegian NGO Aktive Peace Foundation to provide for upfront costs with interest free micro-financing. We hope engaging the communities own resources in this way will help counter the issues we've seen in too many externally funded projects that fall from the sky into a community.

Other simple uses of solar energy include using solar radiation for the purification of drinking water such as with the Solvatten System, ${ }^{25}$ and passive solar lighting and convective cooling ${ }^{26}$ and evaporative chillers. Another potential student design project is to develop a hybrid biomass based fish smoking ${ }^{27}$ and small scale power generations system using a locally grown renewable non-food feed stock ${ }^{28,29}$ Hardwoods have been used for fish smoking leading to severe deforestation. Now, as an alternative Gambians burn other toxic materials to smoke the fish leading to toxins becoming present in the traditional food chain. Fish is a dominant part of the Gambian diet and smoking is a frequently used method of preservation so this problem has potentially widespread health and environmental impacts. Finally, the ubiquitous donkey carts are simple to a fault in terms of safety. Several low cost simple improvements to their basic design could greatly increase safety. Again appropriate technology must be foremost; it does no good to inflate the cost of the existing design beyond what can be practically afforded - it will not be adopted. It also needs to be accepted culturally.

"Progress toward what?" an essential question to ask that will likely have a different answer from the context of the communities we are working with, than our American "technocratic idea of progress [as] a belief in the sufficiency of scientific and technological innovation as the basis for general progress." ${ }^{30}$ Audience member at a seminar on the future of public health at UTG asked "what are we developing toward - can we afford it?" We must listen carefully to our Gambian collaborators and those in the communities we hope to help. The communities themselves should be the driving force behind any projects. We asked our UTG students to suggest where they saw needs in their communities: improved drainage systems for the numerous villages and areas flooded every year during the rainy season, improvements in the reliability of the public electric power system, improved road design regarding drainage as well as traffic management, waste management, and a health center incubator.

\section{Conclusion}

A peer to peer collaborative structure for service learning projects in developing countries has been initiated in the developing country The Gambia. These projects are being developed in parallel with a curriculum development projected featured in a companion paper. The model adopted attempts to break away from the typical cycle of Western "experts" solving poorly 
understood problems in developing countries. Evidence suggests that such projects only increase dependency and the need for additional aid. By focusing on the development of local experts who are part of the community, we hope to produce an environment where Gambians work within local resources to solve community based problems autonomously.

The summer after the completion of the two PV projects described, a community in Buniadu Village approached some of the UTG students looking for help powering their mosque. A group of students went out to the site and designed a complete PV system meeting the mosque's needs. The community covered the costs of all the required equipment. On installation everything worked and was still working perfectly to date. Our hope is that this is just a small example of what might be possible with the collaborative, locally funded, approach outlined here.

\section{Works Cited}

1. Oakes, W. Creating Effective and Efficient Learning Experiences While Addressing The Needs Of The Poor: An Overview of Service-Learning in Engineering Education. American Society for Engineering Education, 2009.

2. Fikkert, B.; Corbet, S.; Campbell, D. When Helping Hurts: How to Alleviate Poverty Without Hurting the Poor. and Yourself; Moody, 2009.

3. de Negri, B.; Thomas, E.; Ilinigumugabo, A.; Muvandi, I.; Lewis, G. Empowering Communities: Participatory Techniques for Community-Based Programme Development. Vol 1. Trainer's Manual (Participants Handbook). Population Communication Services. pcs.aed.org/documents.htm (accessed 2011).

4. Nieusma, D.; Riley, D. Designs on development: engineering, globalization, and social justice. Engineering Studies 2010, 2 (1), 29-59.

5. Calderisi, R. The Trouble with Africa: Why Foreign Aid Isn't Working; Palgrave-MacMillan, 2006.

6. Easterly, W. The White Man's Burden: Why the West's Efforts to Aid the Rest Have done so Much I'll and So Little Good; The Penguin Press, 2006.

7. YEP!Africa. March Newsletter March 2010, 2010. issuu.com/yepafrica/docs/yepnewsletter_2_march_2010 (accessed 2011).

8. Duffy, J. Village Empowerment: Service-Learning with Continuity. International Journal for Service Learning in Engineering 2008, 3 (2), 1-17.

9. Engineers Without Borders. Strategic Plan, 2010. www.ewb-usa.org/theme/library/about-ewb-usa/ewb-usastrategic-plan-2010.pdf.

10. Thilmany, J. Tuning In - Cross-Cultural Design Puts a New Spin on Human Factors Engineering. ASME Mechanical Engineering magazine, Jun 2010.

11. Radcliff, D. What would Jesus do — or would he? Messenger Magazine, Brethren Press, July/Aug 2010.

12. Farmer, P. Personal conversation; Elizabethtown College, April 2009.

13. Al-Khafaji, K. Learning Sustainable Design through Service. International Journal for Service Learning in Engineering 2006, 1 (1), 1-10.

14. Ofosu, W. K.; Sekyere, F. Using Service Learning in an Engineering Program in Ghana. International Journal for Service Learning in Engineering 2008, 3 (2), 42-49.

15. Kammen, D. M.; Dove, M. R. The Virtues of Mundane Science. Environment: Science and Policy for Sustainable Development 1997, 39 (6), 10-41.

16. Nieusma, D. "Sustainability" as an Integrative Lens for Engineering Education: Initial Reflections on Four Approaches Taken at Rensselaer. American Society for Engineering Education, 2009.

17. McGarvey, K. Engineering Innovators without Borders: Developing Entrepreneurial Opportunities for the Developing World through Engineering Redesign. International Journal for Service Learning in Engineering 2009, 4 (1), 48-61.

18. Kelley, B. B. W. T. J. Student-Aimed Appropriate Technology Engineering Projects in Kenya. ASEE Gulf- 
Southwest Annual Conference, 2006.

19. Moss, T.; Pettersson, G.; van de Walle, N. An Aid-Institutions Paradox? A Review Essay on Aid Dependency and State Building in Sub-Saharan Africa; Working Paper No. 74; The Center for Global Development, 2006.

20. Guest, R. The Shackled Continent; Smithsonian Books , 2004.

21. McConville, J. R.; Mihelcic, J. R. Adapting Life-Cycle Thinking Tools to Evaluate Project Sustainability in International Water and Sanitation Development Work. Environmental Engineering Science 2007, 24 (7), 937 948.

22. Montgomery, M. A.; Bartram, J.; Elimelech, M. Increasing Functional Sustainability of Water and Sanitation Supplies in Rural Sub-Saharan Africa. Environmental Engineering Science 2009, 26 (5), 1017-1023.

23. Kamkwamba, W.; Mealer, B. The Boy Who Harnessed the Wind; Harper Collins, 2009.

24. Pugh, S. Total Design: Integrated Methods for Successful Product Engineering; Addison Wesley, 1991.

25. Wadström, P. Container for purifying water by utilization of sunlight. CN 101068578 (A) European Patent Office, 2007.

26. Prasad, D.; Jason, V. Homebush Newington Village, Environment Design Guide, 1998. www.netspeed.com.au/abeccs/newington/newington.htm (accessed 2011).

27. Feka, N. Z.; Chuyong, G. B.; Ajonina, G. N. Sustainable utilization of mangroves using improved fish-smoking systems: a management perspective from the Douala-Edea wildlife reserve, Cameroon. ; , Vol. 2 Issue 4. Tropical Conservation Science 2009, 2 (4), 450-468.

28. US Department of Energy. Small Modular Biomass Systems, , 2002; GO-102002-1676; DOE, 2002.

29. Stassen, H. Small-scale biomass gasifiers for heat and power: a global review; technical paper ; no. WTP 296. Energy series; World Bank, 1995.

30. Marx, L. Does Improved Technology Mean Progress? Technology Review, Jan 1987, 33-41. 